\title{
Introductory Comments:
}

Presented for the Digital Mapping Techniques 2012 workshop, May 20 - 23, 2012, in Champaign, Illinois. Presentation was created and delivered by Jennifer Athey, Alaska Division of Geological \& Geophysical Surveys (DGGS).

For more information, please contact: Jennifer Athey, DGGS 3354 College Road

Fairbanks, Alaska 99709-3707

E-mail: jennifer.athey@alaska.gov

Phone: (907) 451-5028

Date: August 7, 2012

Published by: Alaska Division of Geological \& Geophysical Surveys, Department of Natural Resources, 2012. Digital forms of this and most other DGGS publications are available on the DGGS Web site (http://www.dggs.alaska.gov). To purchase printed reports and maps, contact DGGS by phone (907-451-5020), e-mail (dggspubs@alaska.gov), or fax (907-451-5050).

Reviewed by: Paula K. Davis, August 6, 2012

In the absence of a speaker, slides have been annotated to improve clarity. 


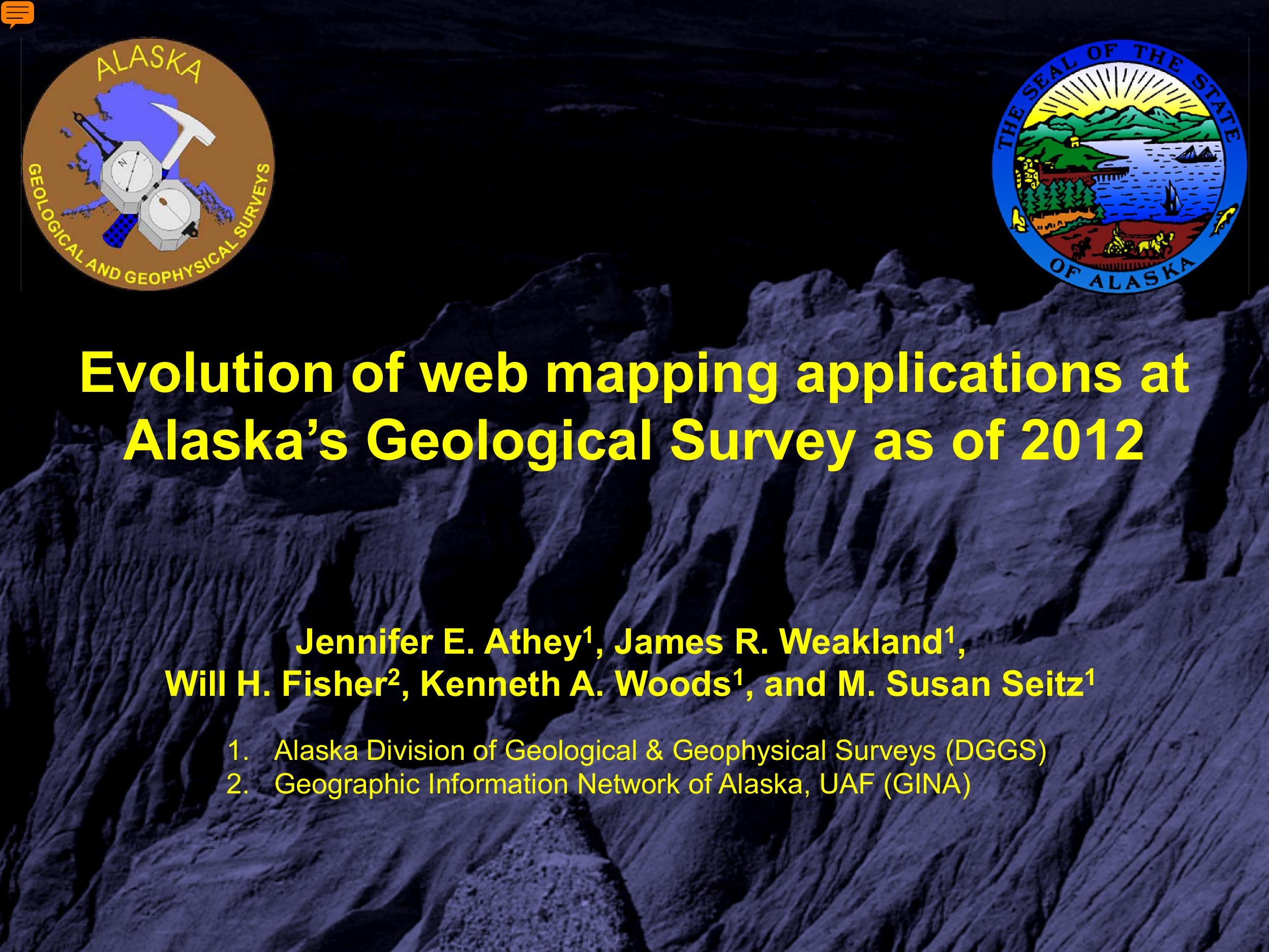




\section{Digital Geologic Data is the Future}

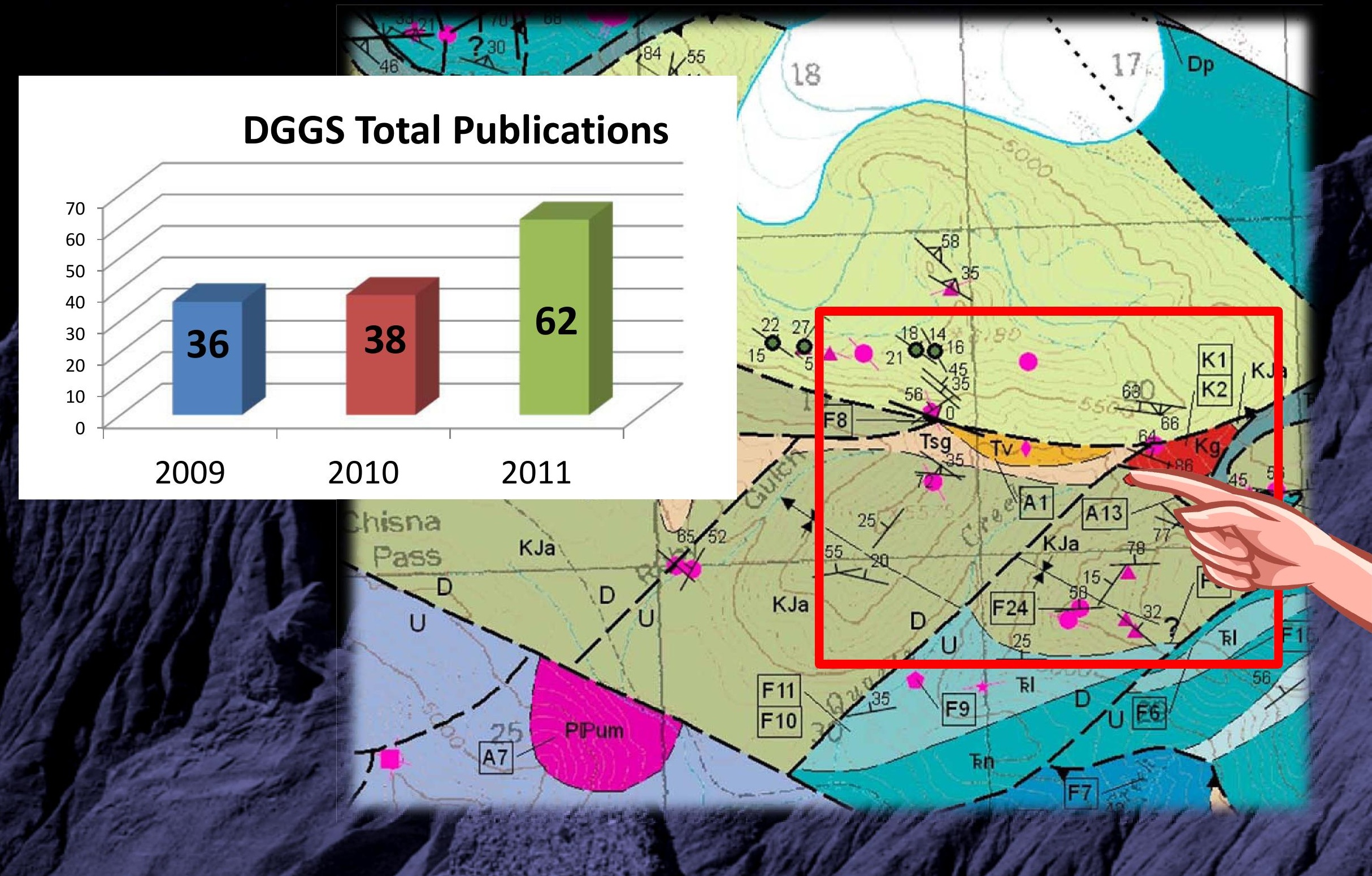




\section{Available Tools}

Open Source Software - overwhelming choice

- Open standards facilitate data interoperability

- People share code back to the community

- No vendor lock-in

- Lower maintenance cost allows for more staff funding

- Data maintenance and outreach are manual

Commercial Software-ESRI's ArcGIS Server

- Users are already familiar with ESRI software

- Easy to implement.

- Facilitates interconnected data

- Specific system and data requirements to meet 


\section{Factors that drive what tools to use}
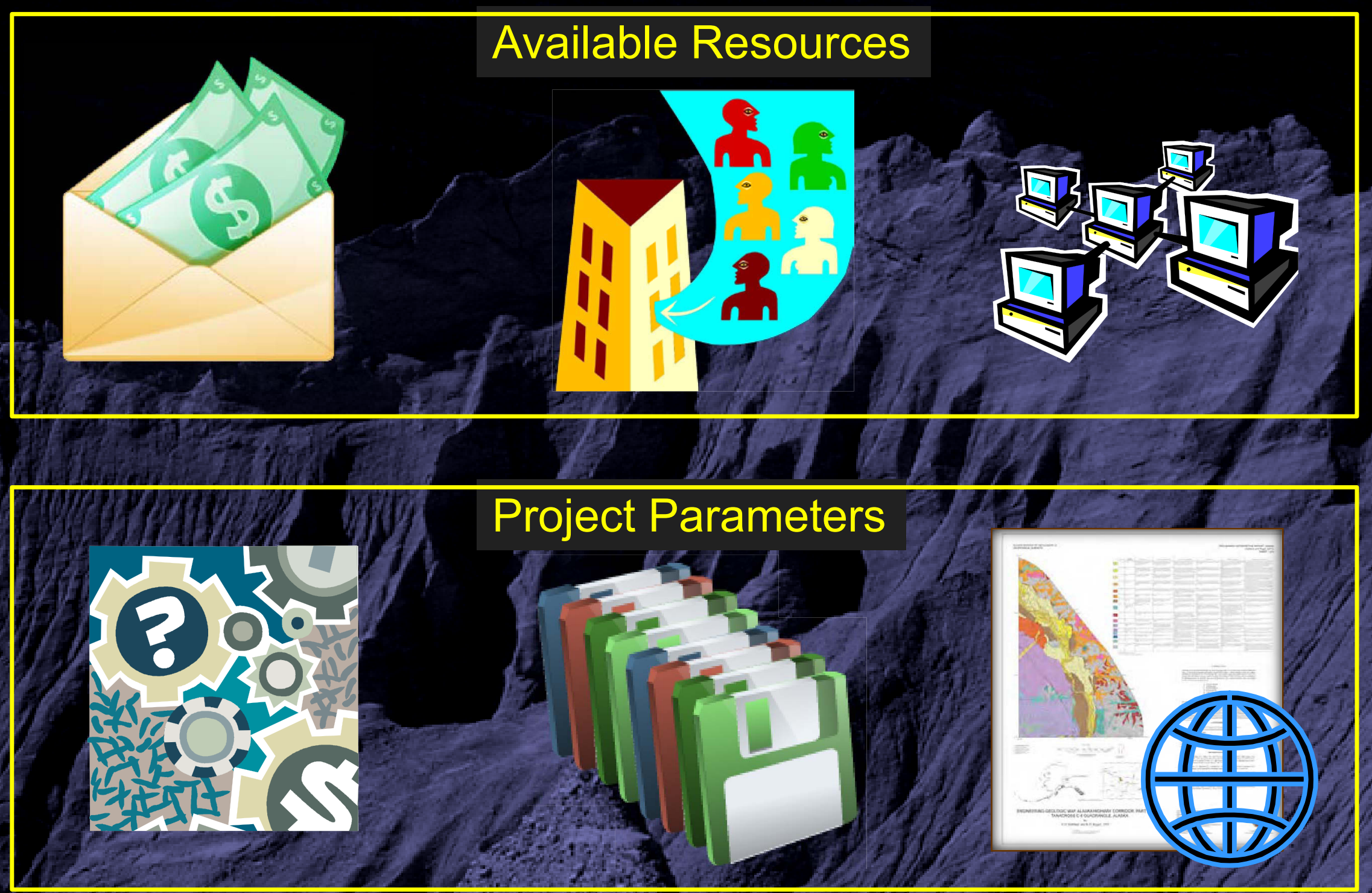


\section{Can we build it? Yes, we can! \\ (Uh, I think so...)}

Who has the expertise to build it and maintain it?

Will your IT infrastructure support it? Is it sustainable? 


\section{Geologic Map Index of Alaska - beta}

\section{Server \\ [Oracle] \\ Connects via ActiveRecord (maps relational data to objects in programming)}

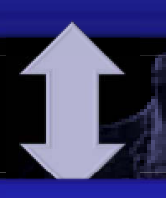

Ruby on

Rails 3.1

Client [Web Browser]

Open Layers 2.11; Ext JS 4.1
(Extended JavaScript library)
(user interface toolkits for web

Open Layers 2.11; Ext JS 4.1
(Extended JavaScript library)
(user interface toolkits for web

Open Layers 2.11; Ext JS 4.1
(Extended JavaScript library)
(user interface toolkits for web applications) Sends out JSON feed to browser (standardized data exchange language) 


\section{Factors that drive what tools to use}
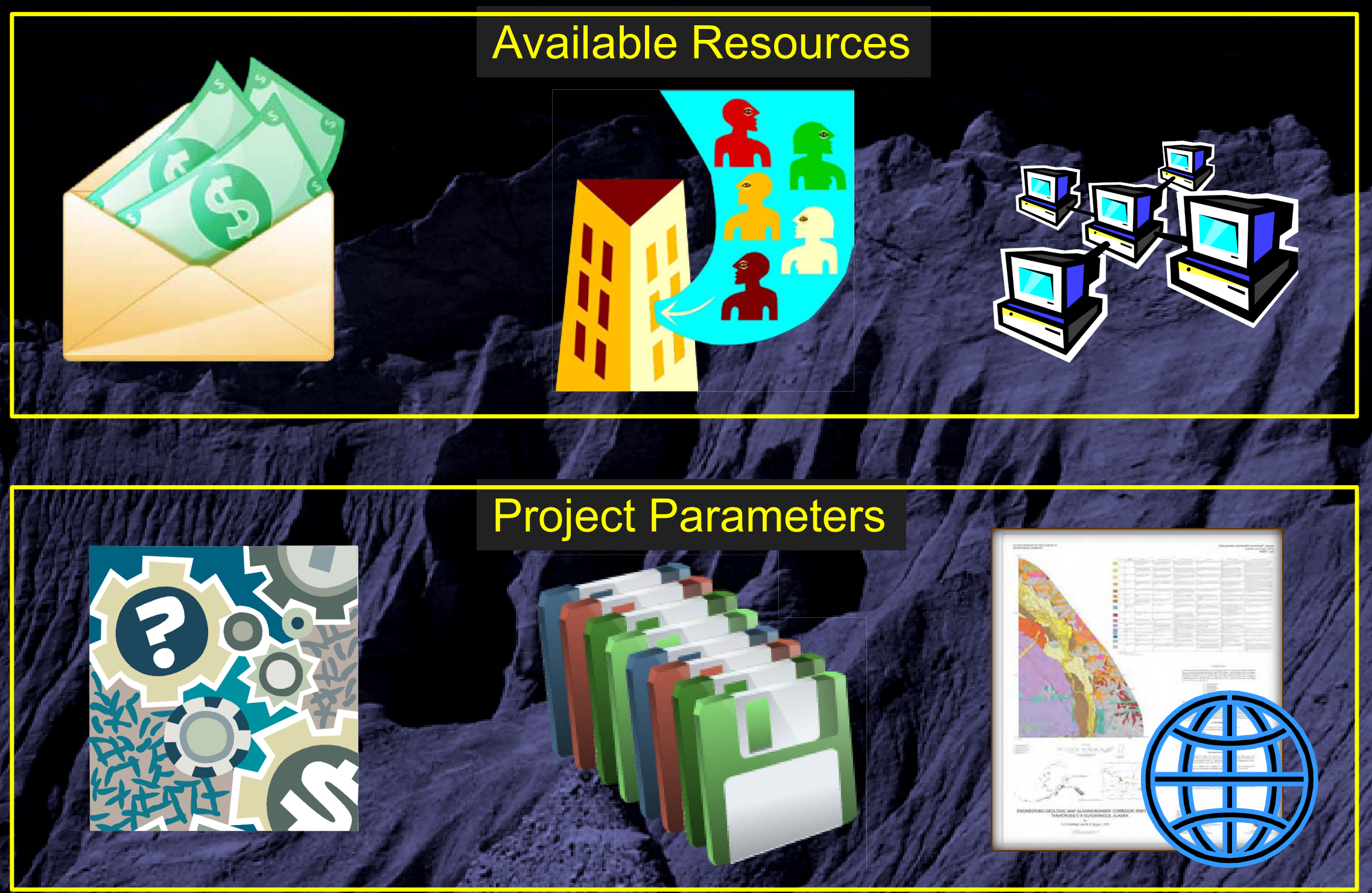


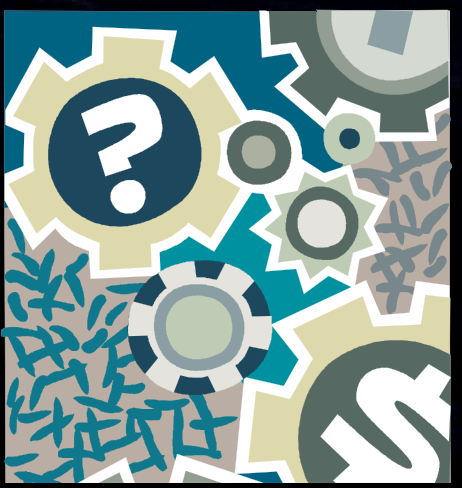

\section{Flexibility is inversely proportional to \\ Ease of Development}

Simple application, minimal to no programmer time, probably easier using ArcGIS Server solution

Complicated application, extensive programmer time, probably easier using Open Source solution 


\section{Alaska Geologic Data Index - beta}

\section{Server \\ [Oracle] \\ Connects via Hibernate (maps relational data to objects in programming)}

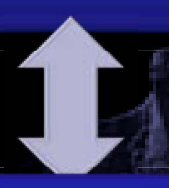

Java

Client [Web Browser]

Sends out JSON feed to browser (standardized data exchange language)

Open Layers 2.11; jQuery UI 1.6 (user interface toolkits for web applications) 


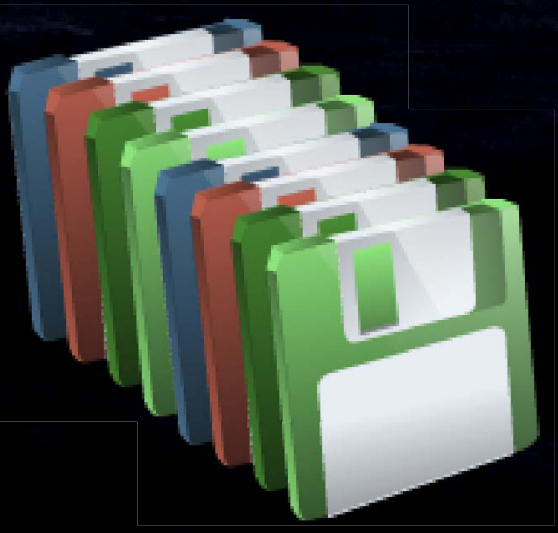

\section{Optimize data transfer to cut} back on server hits and speed up user data requests

\section{Server side}

- Manages access to data Transforms delata to make interpretable tor. client Indexes dalla

\section{Client side} server

Renders the data 


\section{Alaska Airborne Geophysical Data - beta}

Server [ArcGIS Processes data and outputs Server] services

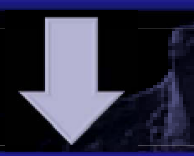

WFS/WMS

Client [Web Browser]
Interface standard

Pulled down using JavaScript; displayed to user with Open Layers 2.11; jQuery UI 1.6 (user interface toolkits for web applications) 


\section{As Yet Unanswered Questions}

- When we start getting a lot of traffic, how will they perform?

- Is ArcGIS Server best tool for web maps?

- Do we need to switch to one type (philosophy of minimization)?

- Will serving out geodatabase data internally be successful?

- Haven't done Arc multiuser geodatabase yet.,.

- Implications for GIS storage in Oracle vs. an Arc geodatabase

- Move away from Oracle?

-Would Arc costs be feasible if State pulls funding? 


\section{No magic bullet}

\section{Do what's easier to get done...}

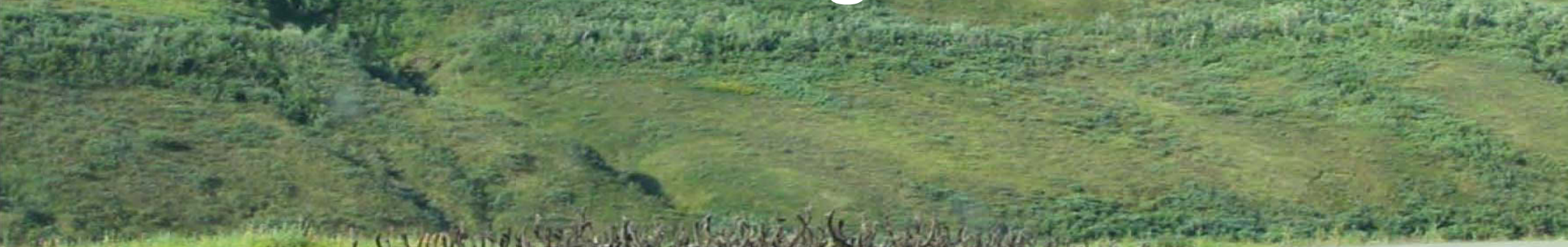

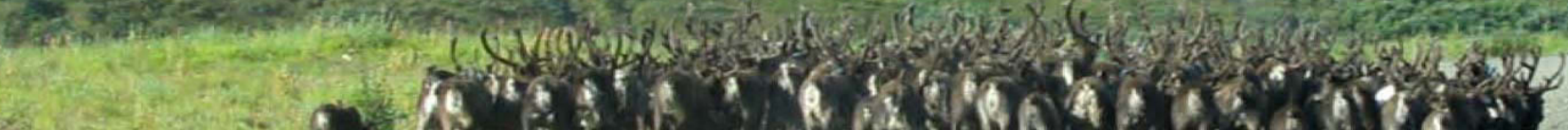

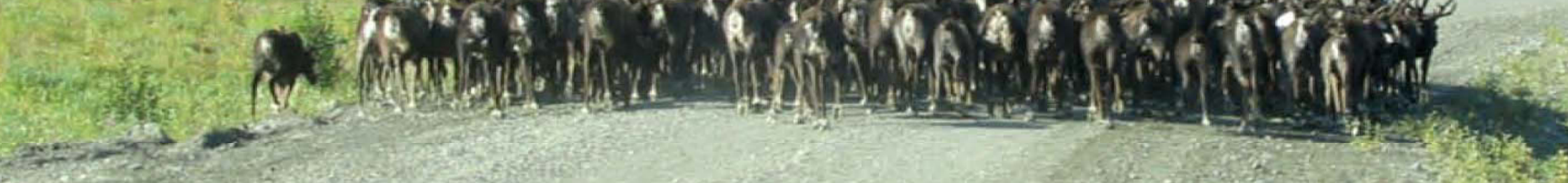

Hire a programmer. Give them a dark room and lots of caffeine. 